\title{
Juxtaposition of lyric and politics in Audenesque
}

\section{Anamika Sharma}

College of Arts \& Science for Girls, Prince Sattam bin Abdul Aziz University, Kingdom of Saudi Arabia. a.sharma@psau.edu.sa; anamikasharmajaipur@gmail.com

\begin{abstract}
This paper aims to loosen the established taxonomy of Auden's political works. We will see that in the sustained attempt to engage with each lyric, we cannot confine our discussion to the level of content alone. This is the central tenet of my approach to the political Auden.

I will demonstrate that the content of political argument in a given work can only be meaningfully explained if we understand the basis on which the lyric finds its voicing. The peculiar kind of magnetism of Auden's political lyrics in which, I include earlier works such as "Control of the Passes" and "Get there if you can".

Keywords-Juxtaposition, Audenesque, lyric.
\end{abstract}

\section{INTRODUCTION}

What relationship can we ascertain between the nature of modern politics and the workings of the lyric in Auden's hands? If the lyric is so opportunely placed as to realise decisive moments in thinking, on what kind of basis would we describe a given moment as political?

The reconstructive, ideational approach can encourage us to regard his works as itemisations of political trends, with an unreflective equation made between poet and belief. This risks the critical ossification of Auden's works, fixing them as part of a historical narrative first and foremost, their generative power as art coming a distant and unsatisfactory second.

Here our revised definition of lyric begins to demonstrate its value. We are licensed to liberate the lyric from its traditional moorings in intimacy and subjectivity by the compound of private and public, social and political which, together, comprise the experience of life in mass society.

\section{THE NATURE OF THE POLITICAL IN AUDEN'S WORK}

Lyric's privilege of the speaking voice - the way that, through its vocality, lyric fosters the colloquy between reader and imagined speaker - amounts to a proxy rehearsal of kind of interlocution upon which politics depends. The quality of outward projection that inheres in Auden's lyric voice has an appreciable contiguity with political action.

If (authentic) politics is configured as speaking in public about public affairs, and is a kind of performance, then it is necessarily finite. It needs protection, needs a sphere in which it can be recognised and remembered. Arguing against the totalitarian monolith, only the continuation of a public realm built upon the recognition of human plurality can safeguard political speaking.
As before, it is the element of temporality in lyric which helps us to explicate this common sense of finitude. Throughout the following selection of poems, Auden's speakers are exercised, as they have been previously, by the confusion between the public and private realms. More specifically, the removal or loss of a stable public realm in the modern age is the source of an anxiety for permanence (in its own way a conditioning factor in the rise of totalitarianism in the late twenties and thirties), which in turn animates the lyric speaker to evoke a greater, and greatly dislocating, sense of finitude. So the practice of reading these poems prefigures Arendt's point:

It is the publicity of the public realm which can absorb and make shine through the centuries whatever men may want to save from the natural ruin of time. Through many ages before us - but now not any more - men entered the public realm because they wanted something of their own or something they had in common with others to be more permanent than their earthly lives....There is perhaps no clearer testimony to the loss of the public realm in the modern age than the almost complete loss of authentic concern with immortality, ...

The modern political moment, as attested in lyric, is the cogent expression of such finitude. What we see in Auden's political lyrics, predictably given the time of their composition, is the vestigial ethos of Enlightenment optimism regarding the sanctity of the public realm and the instructive purpose of history effectively facing the sunset of its truth value. Crucially, the temporal element of lyric vocality - the sense we have of an unfolding utterance which we in turn speak for ourselves - secures our understanding of the experience of this tectonic shift, making our involvement active rather than passive. The speakers of the poems (and this is why a critical approach based exclusively on Auden himself might be too selective) each inhabit a singular, finite moment in the 
process of confronting the collapse, or perhaps, mutation, of the public realm. They might, as in "Control of the passes", render this confrontation in a third person minor narrative, a quasi-dramatic account that manipulates the poetics of the sonnet; they might, as in "Get there if you can", perform a kind of imaginative osmosis, the speaker himself becoming the recipient of a dissipated cultural energy.

Focusing on the vocality of lyric in this wider political context means allows us to expand our sense of what constitutes the political in Auden's work. Where the mode of a lyric is transparently argumentative, or seems to exposit a point of view that we could classify according to political dogma, then a critical response is self explanatory.

Auden's early thematic preoccupation with the silent coercion of a faceless majority, and the catastrophic consequences for the inner life, demonstrate eloquently enough how alive is his work to the conditioning factors of thinking. But the matter becomes more complex when we consider the political in the Arendtian sense, of what modes of coexistence are made available at a given historical point. In some examples such as "Get there if you can" the polemical thrust that powers the lyric aims directly at this question. But the real value of Auden's lyrics (and my close readings have been selected because of this) lies in their continual ability to show the thinking process behind the utterance: the background of thought, the accretions of historical modes of thinking and living, and their collisions with newer modes, which together amount to their manner of perception.

This philosophical lexicon ought not to detract from the poems themselves, and it is clear that Auden's is not an art which turns away from human affairs, in order to better record their nature: quite the contrary. His political poems are valuable because they are frequently pitched into the breach between that which is historically inherited or conditioned and what is within the realm of the speaker's agency, in the very entanglements of the world. In their vocal, finite quality they describe the beginnings of the political moment; in their ideas and argument they address how it can be manifested. It is this, their three hundredand-sixty-degree aspect, their glance backwards and forwards, which we can call Heideggerian because it is redolent of the breadth that Heidegger sees in the realisation of the finite moment of thinking. The spoken lyric is the artistic realisation of the contingency of thought, and Auden's political lyrics explore this in significant depth.

The political moment, we will see, takes account of the expanse of its conditioning factors, and according to the conventions of lyric, this expanse is compressed. It is here that I invoke Adorno's conceptual framework, again with a number of caveats. I follow Adorno's thesis that lyric instates a truth that is supra-subjective. The measure of its objectivity lies in precisely the manner that it recounts its conditioning factors: how the objective has been submerged, and is processed by the subjective. Furthermore, although my readings are concerned to describe the historical milieu in which the lyrics were created, Adorno's arguments are instructive for their neat balance between the singular and the historical, a balance which is salutary in the context of political poetry, where the historical threatens to dominate:

Lyric poetry is not to be deduced from society; its social content is precisely its spontaneity, which does not follow from the conditions of the moment. But philosophy (again that of Hegel) knows the speculative proposition that the individual is rendered through the general and vice versa. This can only mean here that resistance to social pressure is not something absolutely individual.

Peter Porter reminded us earlier that the question of what belongs to history and what belongs to the poem is misleading, and Adorno's position reserves a place within the experience of lyric where the reductive historical approach cannot intrude: this is the mark of art's singularity. His move is to claim this place as evidence of art's resistance to "social pressure". Where Adorno sees a representative spontaneity - an expression of opposition in lyric that, ipso facto, must be general - we can divine another way of involving the activity of reading lyric poetry in a context that exceeds the aesthetic. The spontaneity that excites Adorno is activated in speaking the lyric, and by configuring the lyric as being spoken to us. Here Adorno's critique and Arendt's authentic politics coincide. Whether the poem is monodic or choral, the colloquy installed has symbolic value as an emblem of the speaking, which amounts to what MacNeice called in 1938 "a tiny measure of contribution" in Modern Poetry; a gesture of communication - sometimes compromised between poem and reader. From this basis, the life of each lyric and their respective political natures can be better conveyed.

\section{POLITICAL LYRICS}

"Control of the Passes was, he saw, the key": January 1928.

\section{The English Auden, 25}

The formal peculiarity of this early poem presents us with the most inviting explanation of its significance. A sonnet that foregoes the first person and that veils its musicality in favour of a novelistic third person narrative, "Control of the Passes", sketches a version of political life by proxy. The notes of intimacy that traditionally colour the sonnet 
form - those characteristic suggestions of self-exposure are denied us here. Having elected to use the third person, Auden confuses our grounding with the sonnet. Where, or who, we ask, is the addressee of the poem? This is our "key", as readers, to the "new district" availed by the poem, though the fate of the agent himself, whose confusions are parabolic, allows no such success.

The first quatrain suggests that the poem has dismantled such a channel of address; it has, through the figure of the agent, a vacuum as its addressee: the agent's absent fellow men, and by extension, we the readers:

Control of the passes was, he saw, the key

To this new district, but who would get it?

He, the trained spy, had walked into the old trap

For a bogus guide, seduced with the old tricks.

The "new district" might present of a new way of beingwith to the beleaguered spy, a more substantial mode of human interaction that could correct his current self inflicted isolation. But his lexicon, his mother tongue, is the source and function of this isolation. It is rational, inquisitive and acquisitive ("Control...the key / ....who would get it?"). "Control of the Passes" dramatises in miniature the way in which quantification and rationalisation ("old tricks", stalwarts of the Enlightenment) continue to shape the character of modern consciousness, and most perilously, modern notions of communal life. The artistry of the poem lies in its carefully concealed music which, juxtaposed with the neutrality of the third person narrative, hints at the defining anxiety of a life trapped in an inherited subjectivity. The subtly chiming vowel shapes and sounds ("trained spy....bogus guide") do not awkwardly disrupt the cool-headed narration of the agent's dilemma; rather, they pass below it barely noticed, as if encased under ice.

In the imaginative logic of the poem, the rationalising epoch breeds isolation which in turn breeds opposition and conflict. Conflict is the practice that collates with the theory of the rational subject born into the lineage of the Enlightenment. The extended metaphor at work in "Control of the Passes" recounts through the agent's situation and failed mission the recent history of human technological advances and mastery of nature:

At Greenhearth was a fine site for a dam

And easy power, had they pushed the rail

Some stations nearer. They ignored his wires.

The bridges were unbuilt and trouble coming.

The very operation of this metaphor contains the crux of modern isolated subjectivity.

The metaphor takes the macro - the language and attitude of instrumental thinking - and has it represent psychic minutiae. There is a kind of inversion at work here: an erasure of the particular by the power of the general. In doing so, the poem conveys the unsustainable paradox of the subjectivity in question; we can read "Control of the passes" as a eulogy for the inner life. Yet, again, the agent's perspective is one instance of the essential problem. The agent assumes the problem to be one of mere positioning ("had they pushed the rail / Some stations nearer"); if human effort were more fully exerted, the acquisition of more power and greater mastery would suffice.

Alternatively, the agent's desire to connect (and the fact that his communications are ignored) suggests his more profound understanding of the cause of conflict. This aspect accounts for those readings which see the poem as self-commentary, the agent representing the poet. In sustaining both alternatives the narration emphases the incisive power of the lyric to crystallise, in the Adornian manner, an epochal contradiction. But the adumbrating problem is always the question of being-with: how to analyse its current failure, and how to imagine other, more rewarding ways of communal living.

The volta of the sonnet is employed by Auden to bring forth a new intensity, as in the climactic sextet we are given a deeper psychological insight into the agent's situation:

The street music seemed gracious now to one

For weeks up in the desert. Woken by water

Running away in the dark, he often had

Reproached the night for a companion

Dreamed of already. They would shoot, of course,

Parting easily who were never joined.

Human culture, the vibrancy of the "street music", strikes the agent at an aesthetic distance, lending him no greater insight or involvement, and is experienced as a curious interlude within his dreamlike subjectivity. Indeed, the music seems to emanate independent of any human source, and shares an obscure provenance with "they". The agent is posed with a non-choice, between a half life lived in the service of "them", or a flight into the darkness, following the water (it is unclear whether the subject of the third line is the "water" or the agent himself). The cryptic role of the dreamed companion can only be explicated in the agent's death. To shoot him would be to shoot someone else too: the companion is the (imagined) source of human connection that each isolated subject potentially inhabits. "Control of the Passes" is parabolic, then. It is the symbolic moral imperative of the surrogate - that I could be you, and you could be me - ultimately embodied by the agent. In his fate we see this squandered and denied. Auden's interpolation of the last line of the Anglo Saxon poem "Wulf and Eadwacer" - "Parting easily who were 
never joined" - becomes a droll commentary on this irony, and echoes the jaundiced, cynical desperation which the first quatrain offered. Potential is not enough: there seems to be no answer to the double-bind that isolated, rationalising subjects and their correlative insistence on power together create. "Control of the Passes" suggests that the politics of mass society is predicated on the removal or invalidation of any middle ground between the stringently subjective (which means isolation) and the implacable objective (which means self-denial or subjugation). The ease with which the poem traverses the two comprises its final importance. Seamlessly woven together into a perceptual whole in the poem, this traffic between subjective and objective is exactly the kind of freedom which is precluded for the agent. In mimetic terms, the lyric's perception imitates a wish, then, rather than reality. In speaking the lyric reader becomes narrator, implicated in the deadly paradox of the agent's situation. We recall what the sonnet form entails: the complicated marriage of proximity to and distance from the reader contained in "Control of the Passes" signifies an early success for Auden in reworking established forms to more accurately diagnose the nature of modern collective life.

"Get there if you can and see the land you once were proud to own" - April 1930. The English Auden, 48-49.

Does a viable mode of action, understood in Hannah Arendt's sense, subsist in the age of mass society? Can we find such a mode from among the husks of mere "behaviour", action's modern-day progeny? What roads are open to those who would intervene, or seek to change their circumstances? "Get there if you can" presents an interesting test case for these questions. The poem confirms Auden's preoccupation with the psychological realm as the locus of political change and in doing so declares his intellectual allegiance to "behaviour", at least by proxy. It is, however, a fraught allegiance. In its pronominal shape - which lurches between a vocative address to a general "you", and exhortative pleas to better "our" condition - the poem rehearses a series of ways of being-with, where all are determined by a perceived crisis. Crisis galvanises and polarises simultaneously, and the panoply of collectives presented by the lyric, whether psychological, economic, historical or intellectual, would seem to comprise a range of possibilities that the speaker is attempting to surpass. In this sense the lyric could be said to have other, less local targets than the "puritan middle class" identified by John Fuller; more ambitiously, it imitates the processes by which mass society continually divides its internal components. So again, we have a poem seeking a solution to a problem that it unwittingly perpetuates. The lyric's characteristic energy typifies the restless will to differentiate which is a symptom of the behavioural paradigm. In its pace, then, "Get there if you can" represents the labile speed of those societal divisions which work against any fixity of being-with, even as it aims to challenge them, offering a gesture of desperate defiance realised in the long, stalking line borrowed from Tennyson's "Locksley Hall Sixty Years After." As we speak them, the range of vowel sounds seems to be exhausted by each line ("Power-stations locked, deserted, since they drew the boiler fires"); pace takes precedence over internal music, the pointed full rhymes cement each couplet as a stand-alone rhetorical attack. "Get there if you can" is a mass society choral poem par excellence: its togetherness is contingent upon impending trauma or disaster, and is given by a historical inheritance that persists only insofar as it limits or constrains the individual in the present.

The visual emphasis of the opening couplets, their litany of industrial collapse and entropy, is one of the most memorable instances of the oft-remarked cinematic quality of Auden's early work. Yet the elemental point here which is much more tangible when we speak the poem - is the imaginative pollination of vitality, from the abandoned workplaces, the "Smokeless chimneys" and "rotting wharves", to the speaker as seer. This vitality is manifest in the pace of the lines. It is as though the memory of such concerted activity and purpose exists virtually now, in the speaker's account, as it happens. Its pace affords the lyric a sense of discrete occasion, which is another way of putting what John Bayley calls Auden's "stylishness". Style is the instatement of the lyric moment. The speaker's ersatz possession of that cultural energy is a reclamation of inheritance through the force of imagination, now that it cannot be possessed in real terms ("...the land you once were proud to own"). When we speak the lines aloud the effect of their pace is irresistible, and we receive an intimation of the kind of vigour which the speaker is desperately trying to revive.

Herein lies the true value of Auden's early lyrics: through their vocality, they frequently testify to the perceptual force of an imagination seeking to surpass its own "behaviour". Images of access pursue this trajectory; the speaker attempts to enter the edifice of industrial history in search of a stronger mode of possession than the virtual:

Squeeze into the works through broken windows or through damp-sprung doors;

See the rotted shafting; see holes gaping in the upper floors;

All we can do, though, is "see": the imperatives possess the force of command and, conversely, a note of defeat. But Auden is already demonstrating that in mass society observation stands in the place of action. In twentieth 
century modernity it is, at the very least, bestowed with a new kind of purposive weight. The lyric can reveal this weight. Seeing cannot be said to be entirely passive: it has significance which is politically active, if we define the political as encompassing the perceptual change (here the transition of cultural to imaginative activity) which might then orientate a call for action or force a decision: the backward glance before the forward.

If the collective here is bound by a common lack, and seems to be specifically generational (the young whose cultural and financial security has been squandered), then the next sequence of couplets expands to include all kinds of profligates. The same impetus with which the dead industrial activity is virtually preserved by voice encourages the continual inclusion of others into a shapeshifting collective. It is not that all are included at once: on the contrary, Fuller's argument that the poem concerns the "puritan middle class" is entirely justified. It is rather that the lyric, through its adaptable pronouns, demonstrates how a collective might include and exclude in a discrete historical situation in order to define itself, in an ongoing, provisional way. The privations incurred at the hands of free market economics ("While they quietly undersold us with their cheaper trade abroad;") have bestowed a halcyon glow on the previous period of consumer security ("At the theatre, playing tennis, driving motor-cars we had"). Now, apparently at the time of cultural expiration, the speaker can list those betrayers who form a genealogy of bourgeois thinking, including the world-historical and the personal:

Newman, Ciddy, Plato, Fronny, Pascal, Bowdler, Baudelaire,

Doctor Frommer, Mrs. Allom, Freud, the Baron, and Flaubert.

The combination of the renowned and the obscure serves a special kind of purpose, regardless of whether we know who "Mrs. Allom" might be, for instance. Figures from the personal life play an equal role in defining what is inexorably given to the subject: "Ciddy", "Fronny" et al remain uncannily familiar. In its kinetic style the poem is actively constructing a history for those included in the collective, those who feels themselves addressed by the vocative "you" and implicated by the "us". With a Hegelian flourish, "Get there if you can" suggests that this history is finally being described at the point of the cultural expiration. The couplet above is notable for the curious music it acquires through its concentrated internal rhymes: a note of the ridiculous is entirely congenial to the extreme pace that propels the lyric onward (Stan Smith classes the poem as light verse, borrowing Joyce's term "jocoserious").

The speaker pursues his narrative without pause. Intellectual history, the dyad of science and art ("compelling logic", "beauty of their verse"), and the principle of example on which society is based have precluded the choice of "life" ("Very well, believe it, copy, til your hair is white as theirs.") The lyric struggles to imagine what kind of action might be possible, or whether the cycle of behaviour must be uprooted psychologically. At this impasse the speaker finds the most lucid image for compromised togetherness:

Intimate as war-time prisoners in an isolation camp, Living month by month together, nervy, famished, lousy, damp.

On the sopping esplanade or from our dingy lodgings we Stare out dully at the rain which falls for miles into the sea.

Under the terms of mass society, where does my freedom to be-with reside? These couplets comprise the high point of the lyric, where intellectual force is given an emotional charge beyond the declamatory. The image realises the backward glance - the retrospective construction of history at its expiration - as "we / Stare out dully at the rain...", but is rescued from the abstract by the grim familiarity of the "sopping esplanade" and "dingy lodgings". The cumulative weight of history is looked upon hopelessly. This is a suitable note on which to end, but the gravity of these lines urges the speaker to more questions: where are the messiahs, what role for the visionary in mass society? "Lawrence, Blake and Homer Lane, once healers in our English land", each pioneered their unique oppositional eccentricity, but their respective fates confirmed the victory of behaviourism. The law of the mass is equalisation and so impotence: "Have things gone too far already? Are we done for? Must we wait..." The climax of the lyric gestures toward the milieu of political extremism that Auden and his generation orbited, but this point is secondary. The real value of "Get there if you can" resides in its irresistible logic, tapped afresh as we speak it, which veers towards total collapse: the point at which reactionary politics becomes most appealing, perhaps. There is an explicit awareness of the essential passivity of the democratic collective here ("Must we wait"), though the sentiments, almost theatricalised, are anti-democratic to the point of parody:

Or, in friendly fireside circle, sit and listen for the crash 
Meaning that the mob has realised something's up, and start to smash;

Engine-drivers with their oil-cans, factory girls in overalls Blowing sky-high monster stores, destroying intellectuals?

The intellectual panic at the onset of mass politics is a common trope of histories of modernism; these lines are a coup de theatre of bourgeois intellectual paranoia. For the time, though, the lyric is actually sustained by question marks over its sincerity: they contribute appropriately to the variety of tones and registers which defies reduction to doxa. Such variety captures the clashing registers of collective life, its depths as well as its trivialities - its limit points. The commands at the finale of the lyric - "Drop those priggish ways forever, stop behaving like a stone:" cannot overcome a residual pessimism that amounts to bravura indifference to the fate of the collective:

If we really want to live, we'd better start at once to try; If we don't it doesn't matter, but we'd better start to die.

The hopes for psychology, as the potential sphere of a new kind of action, are tempered by its status as a prominent wing of the behavioural sciences. Nevertheless it remains here the only possible recourse for understanding, and possibly altering, the terms of collective life. Similarly to "Control of the Passes", the lyric itself, as the repository of virtual energy, capable of reconfiguring collective life in its imaginative ways of being-with, elicits in its workings a freedom beyond the reach of the lone voice.

\section{CONCLUSION}

The qualitative separation of politics and poetry is by now a commonplace, but the experience of Audenesque reminds us that they share a significant contiguity in their respective dependency on, and representations of, the temporality and the discreteness of thought.

These poems transcend the period and its controversies because of their fidelity to the ground of thinking: they testify to the conditions for thinking at a given juncture. That is to say, in their aesthetic and its elicitation of our own speech, they preserve the reality of their moment and so furnish us with a diachronic sense of history in which the particularity of the poem's experience and the particularity of our own come into fleeting contact. The qualitative difference between politics and poetry is maintained throughout, and Auden would recurrently insist on this difference in his later career; but perhaps the point needed to be repeated so often precisely because of their essential contiguity, which his early poetry had profoundly recognised and continues to make available to the reader.

\section{REFERENCES}

[1] Arendt, Hannah, The Human Condition. London: University of Chicago Press, 1958

[2] Auden, W. H. Poems. London: Faber and Faber, 1930.

[3] The English Auden: Poems, Essays and Dramatic Writings 1927-1939. Ed.

[4] Davenport-Hines, Richard. Auden. London: Vintage, 2003. First published 1995 by William Heinemann.

[5] Fuller, John. W. H. Auden: A Commentary. London: Faber and Faber, 1998.

[6] Bayley, John. The Romantic Survival: A Study in Poetic Evolution. London: Constable, 1957.

[7] Collini, Stefan. Public Moralists: Political Thought and Intellectual Life in Britain 1850-1930. Oxford: Clarendon Press, 1991. 